\title{
Future trends and emerging issues for nanodelivery systems in oral and oropharyngeal cancer
}

\author{
This article was published in the following Dove Press journal: \\ International Journal of Nanomedicine \\ 26 June 2017 \\ Number of times this article has been viewed
}

\author{
Alexandra Iulia Irimie' \\ Laura Sonea ${ }^{2}$ \\ Ancuta Jurj ${ }^{3}$ \\ Nikolay Mehterov ${ }^{4,5}$ \\ Alina Andreea Zimta ${ }^{2,3}$ \\ Liviuta Budisan ${ }^{3}$ \\ Cornelia Braicu ${ }^{3}$ \\ loana Berindan-Neagoe $e^{2,3,6}$ \\ 'Department of Prosthodontics and \\ Dental Materials, Faculty of Dental \\ Medicine, ${ }^{2}$ MedFuture Research \\ Center for Advanced Medicine, \\ ${ }^{3}$ Research Center for Functional \\ Genomics and Translational \\ Medicine, luliu Hatieganu University \\ of Medicine and Pharmacy, Cluj- \\ Napoca, Romania; ${ }^{4}$ Department of \\ Medical Biology, Medical University \\ of Plovdiv, ${ }^{5}$ Technological Center for \\ Emergency Medicine, Plovdiv, Bulgaria; \\ ${ }^{6}$ Department of Functional Genomics \\ and Experimental Pathology, Ion \\ Chiricuta Oncology Institute, \\ Cluj-Napoca, Romania
}

\begin{abstract}
Oral cancer is a prevalent cancer type on a global scale, whose traditional treatment strategies have several drawbacks that could in the near future be overcome through the development of novel therapeutic and prognostic strategies. Nanotechnology provides an alternative to traditional therapy that leads to enhanced efficiency and less toxicity. Various nanosystems have been developed for the treatment of oral cancer, including polymeric, metallic, and lipid-based formulations that incorporate chemotherapeutics, natural compounds, siRNA, or other molecules. This review summarizes the main benefits of using these nanosystems, in parallel with a particular focus on the issues encountered in medical practice. These novel strategies have provided encouraging results in both in vitro and in vivo studies, but few have entered clinical trials. The use of nanosystems in oral cancer has the potential of becoming a valid therapeutic option for patients suffering from this malignancy, considering that clinical trials have already been completed and others are currently being developed.
\end{abstract}

Keywords: oral cancer, nanoparticle, lipidic nanosystems, polymeric micelles, dendrimers

\section{Introduction}

Oral cancer, especially oral squamous cell carcinoma (OSCC) is a highly prevalent malignancy of the oral cavity, ranking number nine among all cancers at the global level for men. Despite the fact that great progress has been made in cancer diagnosis and therapy, the 5-year survival rate for oral cancers has not improved over the last 3 decades, remaining at approximately $50 \%$ and classifying it as one of the malignant diseases with the worst survival rates. ${ }^{1}$ Taking this into consideration, it can be stated that men are more predisposed to this disease; differences being more related to environmental risk factors than genetic ones. Estimated deaths for men are around 7,000 per year, representing a 17.2\% mortality rate, and for women deaths are 2,700 annually with a $6.3 \%$ mortality rate. ${ }^{1}$ This is due to etiology and major risk factors, represented by a higher consumption of tobacco and alcohol by men.

OSCC is considered a multifactorial disease resulting from genetic and epigenetic mechanisms; environmental risk factors having a significant contribution in the processes of carcinogenesis. The most relevant risk factors are smoking, air pollutants, chronic alcohol consumption, biological agents, and particularly human papillomavirus infection. ${ }^{2,3}$ Nowadays, conventional treatment strategies for oral cancer involve surgical treatment, radiation therapy, and chemotherapy, administered alone or in different combinations. Chemotherapeutic agents used for oral cancer treatment are doxorubicin (Dox) or cisplatin. All these modalities have shortcomings, especially chemotherapy. ${ }^{4}$ These agents exhibit high toxicity in normal cells when administered intravenously, due to their nonspecific tissue distribution. ${ }^{4}$ This leads to the need for
Correspondence: loana Berindan-Neagoe Research Center for Functional Genomics and Translational Medicine, luliu Hatieganu University of Medicine and Pharmacy, 23 Marinescu Street, Cluj-Napoca 40015, Romania Tel +40264450749

Fax +40 264598885

Email ioananeagoe29@gmail.com (c) (1) (5) 2017 Irimie et al. This work is published and licensed by Dove Medical Press Limited. The full terms of this license are available at https://www.dovepress.com/terms.php cc. hereby accept the Terms. Non-commercial uses of the work are permitted without any further permission from Dove Medical Press Limited, provided the work is properly attributed. For permission for commercial use of this work, please see paragraphs 4.2 and 5 of our Terms (https://www.dovepress.com/terms.php). 
lowering administered doses, with the result of increased antitumor effects. ${ }^{5}$ Oral administration of chemotherapeutic agents, although preferred by patients, encounters several problems, because of the low solubility in bodily fluids, low permeability, and poor bioavailability of these drugs. Despite these facts and consequent high costs, the low response rates go hand in hand with a reduced quality of life. ${ }^{2}$ Due to all these facts, there is an increased need for novel and more efficient therapeutic strategies against this disease. ${ }^{4,6,7}$ An alternative to the low response rate is presented by the use of nanoparticle (NP)-based delivery systems as therapeutic agents.

The use of NPs was introduced in oral cancer therapy in order to overcome all the disadvantages of conventional therapeutic strategies. Studies conducted thus far, both in vitro and in vivo, along with some clinical trials, are offering a glimpse into the future of nanomaterial-based therapy for oral cancer, reporting improved results of these drug-delivery systems against oral cancer compared to conventional methods. We summarize the most relevant findings related to different nanosystems tested preclinically for oral cancer, and the most successful prototypes based on innovative nanoformulations that are tested in clinical trials for the same pathology. This overview can be useful for testing novel strategies that can be implemented in clinical management, particularly those using RNA interference.

\section{Nanotechnology-based drug- delivery systems}

In order to overcome the disadvantages of conventional chemotherapeutic agents, molecularly targeted therapies need to be developed, along with their potential for augmenting drug efficiency and concentrations in cancerous cells, while preventing toxicity in healthy cells. Still, cancer cells can also acquire resistance toward these newly developed targeted therapeutic agents. Nanodelivery systems are developed in order to also target this resistance. The loaded particles can have optimal dimensions and can pass through the highly permeable tumor blood vessels and remain in that microenvironment for a longer period, due to the deficient lymphatic drainage. ${ }^{8-10}$

In this context, NPs were introduced in targeted cancer therapy to disable resistance mechanisms and increase curative efficiency. ${ }^{11}$ NPs usually enter cells by endocytosis mediated by receptors, hence avoiding being recognized by P-glycoprotein, a central mechanism involved in chemoresistance responsible for pumping out the chemotherapeutic agents. The use of nanotechnology in drug development introduces novel therapeutic prospects for cancer treatment and involves the use of NPs and devices of $1-100 \mathrm{~nm}$ in size. ${ }^{12-14}$

NP-delivery systems (Figure 1), such as polymeric NPs, liposomes, dendrimers, and metallic NPs, are used to

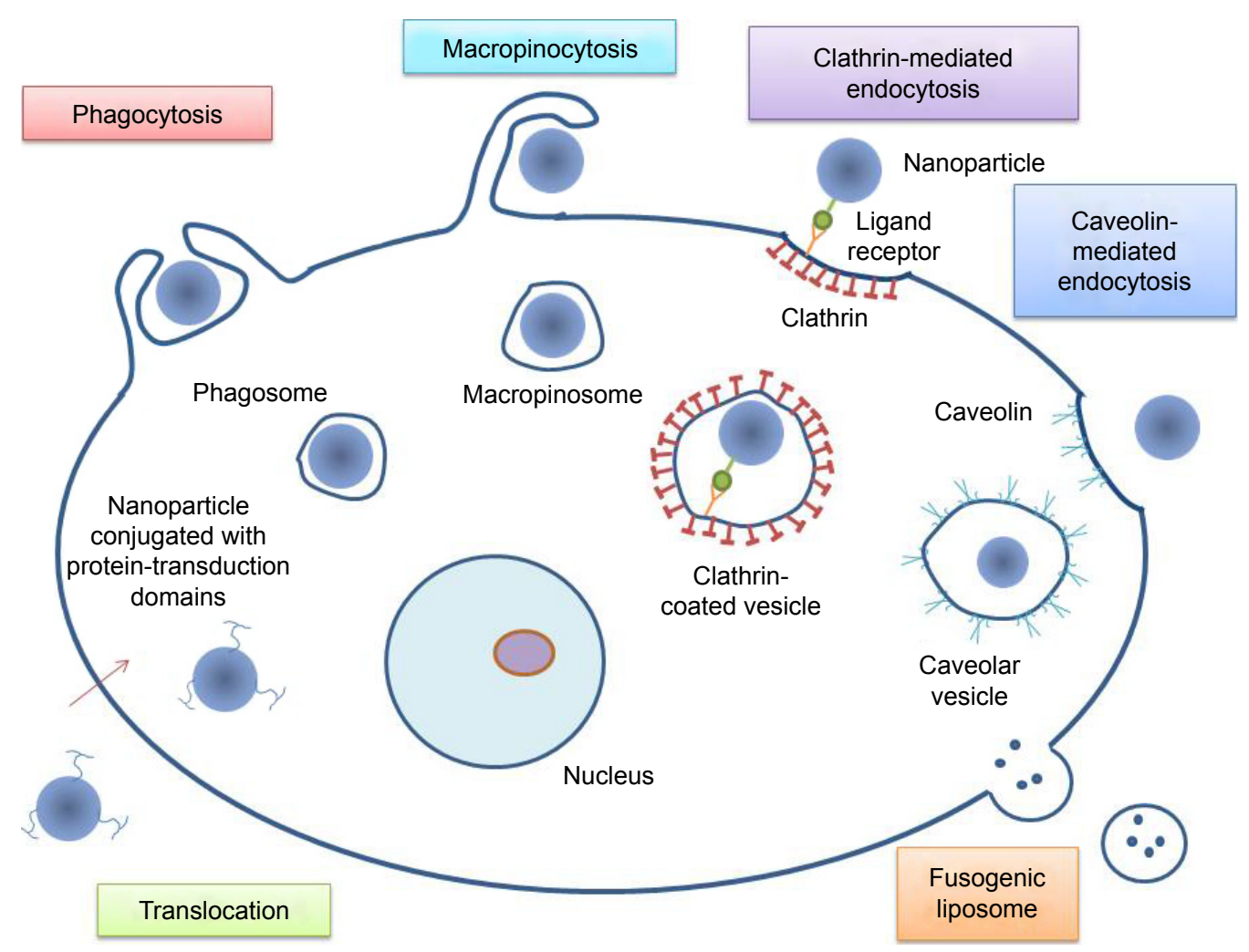

Figure I The main mechanisms of internalization in the case of nanoparticles. 
amplify the main properties of the bioactive agent: absorption, metabolism, distribution, and elimination. ${ }^{15,16}$ Although conventional chemotherapeutic agents are still used on a large scale, NPs are showing an increase in popularity, owing to their adjustable chemical and physical characteristics, as can be observed from the increased number of clinical trials. ${ }^{17}$ There are some newly developed NPs possessing better solubility and bioavailability. For instance, paclitaxel has superior efficacy when bound to albumin in a nanosuspensioninjectable form. ${ }^{14}$ One of the most researched drug-delivery systems worldwide is represented by NPs, which are mainly applied in cancer research. ${ }^{18} \mathrm{NP}$ therapeutics are usually formed by an association between a therapeutic agent, represented by small-molecule drugs, nucleic acids, antibodies, peptides, or proteins and a drug carrier, such as lipids, metals, or polymers. In the majority of the investigated anticancer effects of these NPs, they were proved to be superior when compared to free therapeutic agents, because of their enhanced precision in targeting affected cells and active intracellular delivery. ${ }^{19}$

NPs have been widely used because of their custom-made size, shape, and surface characteristics. NPs can enter cells via clathrin- or caveolin-mediated endocytosis, phagocytosis, macropinocytosis, or translocation..$^{20,21}$ In caveolin-mediated endocytosis, cell membrane invagination occurs in a flasklike shape. Here, the membrane proteins and caveolins bind to the membrane cholesterol and develop the vesicle. This pathway allows the internalization of large particles up to $500 \mathrm{~nm}$ in size. ${ }^{22-24}$ Endocytosis is the process used by cells to communicate with the surrounding environment and internalize molecules. All types of endocytosis begin with membrane invagination, followed by the development of intracellular vesicles. ${ }^{25}$ In clathrin-mediated endocytosis, a coated pit forms with the help of clathrin proteins on the outer side of the plasma membrane. Following the budding of this pit, a coated vesicle of 100-200 nm occurs in the cytoplasm. ${ }^{26}$ The pit formation is triggered by the binding of specific ligands that can be added to NPs as surface receptors. ${ }^{27}$

For phagocytosis to take place, a series of steps must be taken. These are opsonization, contact of the opsonized particle with "professional" phagocytes, and the ingestion of NPs by these cells. During the process of opsonization, the opsonin proteins are recognized and ingested in the phagocytes. If the NPs possess a surface coating able to repel opsonins, like polyethylene glycol or of smaller size, meaning less than $100 \mathrm{~nm}$, they may avoid cellular internalization through this pathway. ${ }^{28}$

Through another mechanism, called macropinocytosis, cells internalize fluids and particles and develop vesicles up to $5 \mu \mathrm{m}$ in size. ${ }^{20}$ The membrane forms protrusions, like in phagocytosis, but instead of engulfing a ligand-coated particle, they collapse and fuse with the membrane. ${ }^{28}$ Another way for NPs to enter cells is by translocation, in which NPs conjugated with protein-transduction domains can pass through cellular membranes in a receptor- and transporterindependent way. ${ }^{29,30}$ NPs can also release their cargo without entering the cytoplasm. This can occur by fusion of the cell membrane with the nanocarriers. Such NPs are fusogenic liposomes constructed by including Sendai virus particles into liposomes. ${ }^{31}$ They have proved to be highly efficient, showing favorable results in the delivery of several molecules, along with increased drug efficacy and low toxicity levels. ${ }^{17,32}$ Ideal nanodelivery systems should be preferentially accumulated in the tumor tissue with the required therapeutic agent, being sustained by the passive- and active-targeting mechanism. The characteristics of nanodelivery systems are summarized in Table 1.

As was mentioned earlier, every NP type has its advantages and disadvantages. Due to its biological-like structure, the lipidic nanosystem has low toxicity on one hand, but on the other hand the cargo release is moderately controlled and the amount of surface hydrophobic loading is also limited. Polymeric NPs have a better control of drug release and enhanced amount of payload; still, the natural polymers are at risk of releasing their cargo before the tumor site. In order to surpass the limitations of these NPs and utilize their advantages, NP multitarget therapy is nowadays proposed, and in some cancer types, such as cervical cancer, it has already been reported to have superior effects..$^{44,45}$ Fundamentally, this can be extrapolated and tested also for oral cancer.

\section{Nanosystem imaging methods}

Investigation of a nanocarrier system can be achieved through a number of methods. The nanocarriers characterization includes defining such properties as size, shape, size distribution, and surface features. Concentration and purity can be examined with the help of dynamic light scattering (DLS), that is based on Brownian NP movement. ${ }^{46}$ Typically, NP characterization is also performed through $\zeta$-potential analysis. The $\zeta$-potential is a key indicator of the stability of NP suspensions, and DLS characterizes particle size and size distribution. ${ }^{46}$

After the particles are characterized, the first layer of biological assessment of their effects takes place in in vitro conditions. In order to follow and quantify the speed of their internalization, two major types of microscopy can be used: fluorescence microscopy and electronic microscopy. Fluorescence and confocal laser-scanning microscopy, where the NPs are fluorescently marked and the fluorescence 
Table I Characteristics of nanodelivery systems used for drug delivery

\begin{tabular}{|c|c|c|c|c|c|}
\hline $\begin{array}{l}\text { Type of } \\
\text { nanoparticle }\end{array}$ & Size & $\begin{array}{l}\text { Type of agent used for } \\
\text { delivery }\end{array}$ & Advantages & Disadvantages & Reference(s) \\
\hline Lipidic nanosystems & $\sim 20 \mathrm{~nm}-\mathrm{I} \mu \mathrm{m}$ & $\begin{array}{l}\text { Amphiphilic drug loading; } \\
\text { hydrophilic anticancer } \\
\text { drugs and siRNA in } \\
\text { the core; hydrophobic } \\
\text { cytotoxic agents on } \\
\text { membrane surface }\end{array}$ & $\begin{array}{l}\text { Long circulation time in blood; } \\
\text { easy modification of surface, } \\
\text { size, charge; active targeting } \\
\text { carriers; biocompatibility and } \\
\text { almost biologically inert; reduced } \\
\text { antigenic or toxic reactions }\end{array}$ & $\begin{array}{l}\text { Limited control of drug } \\
\text { release; stability and } \\
\text { industrial reproducibility } \\
\text { issues; difficulties in } \\
\text { sterilization; drug-loading } \\
\text { capacity low in outer } \\
\text { membrane due to limited } \\
\text { space; intravenous } \\
\text { delivery can lead to } \\
\text { complement activation- } \\
\text { related pseudoallergy }\end{array}$ & $33-37$ \\
\hline Polymeric micelles & $20-80 \mathrm{~nm}$ & $\begin{array}{l}\text { Poorly soluble cytotoxic } \\
\text { drugs; hydrophilic drugs }\end{array}$ & $\begin{array}{l}\text { Long circulation times; smallness } \\
\text { and uniformity lead to better } \\
\text { permeability and distribution }\end{array}$ & $\begin{array}{l}\text { Modification requires } \\
\text { additional chemical } \\
\text { synthesis steps; } \\
\text { insufficient stability in } \\
\text { systemic circulation; } \\
\text { premature drug leakage }\end{array}$ & 38,39 \\
\hline Dendrimers & $10-100 \mathrm{~nm}$ & $\begin{array}{l}\text { Different hydrophobic } \\
\text { or hydrophilic anticancer } \\
\text { drugs }\end{array}$ & $\begin{array}{l}\text { High uniformity; high level of } \\
\text { control over their architecture; } \\
\text { high drug-loading capacity; } \\
\text { multiple functional groups on } \\
\text { their surfaces; drug-release } \\
\text { profiles customizable by } \\
\text { controlled depolymerization } \\
\text { processes }\end{array}$ & $\begin{array}{l}\text { Multistep synthesis that } \\
\text { increases production } \\
\text { costs; higher toxicity } \\
\text { rate; uncontrolled } \\
\text { drug release with } \\
\text { encapsulation }\end{array}$ & 40 \\
\hline $\begin{array}{l}\text { Polymeric } \\
\text { nanoparticles }\end{array}$ & $60-300 \mathrm{~nm}$ & $\begin{array}{l}\text { Cytotoxic drugs can } \\
\text { be encapsulated or } \\
\text { physically entrapped } \\
\text { within a polymeric matrix } \\
\text { (nanospheres) or entrapped } \\
\text { into a cavity surrounded } \\
\text { by a polymeric membrane } \\
\text { (nanocapsules) }\end{array}$ & $\begin{array}{l}\text { Controlled and prolonged } \\
\text { targeted delivery; high stability; } \\
\text { high drug payload; more } \\
\text { controlled drug release }\end{array}$ & $\begin{array}{l}\text { Natural polymers like } \\
\text { chitosan are too easily } \\
\text { biodegradable, not } \\
\text { homogeneous, and need } \\
\text { purification steps }\end{array}$ & $|6,4|, 42$ \\
\hline Metal & $<50-200 \mathrm{~nm}$ & Hydrophobic, hydrophilic & $\begin{array}{l}\text { Nanoparticles can be readily } \\
\text { functionalized with drugs and with } \\
\text { probe molecules; unique magnetic } \\
\text { properties with the ability } \\
\text { for surface functionalization; } \\
\text { potential to be produced with } \\
\text { near monodispersity; absorbing } \\
\text { nanoshells are suitable for } \\
\text { hyperthermia-based therapeutics; } \\
\text { pure; gold nanoparticles are } \\
\text { relatively easy to synthesize and } \\
\text { manipulate }\end{array}$ & $\begin{array}{l}\text { Not biodegradable or } \\
\text { small enough to be } \\
\text { cleared easily; potential } \\
\text { accumulation in the body, } \\
\text { which may cause long- } \\
\text { term toxicity }\end{array}$ & 43 \\
\hline
\end{tabular}

intensity determines the extent of cellular uptake, study cellular uptake of NPs. ${ }^{47}$ Fluorescent microscopy uses the properties of an NP-bound fluorophore, which after being excited with a short-wavelength, high-energy light beam tends to begin the recovery of its low-energy, stable state, during which it will emit light in the visible spectrum. NPs commonly combined with fluorophores are silica-based, polymers, gold NPs, and upconverting NPs. ${ }^{48}$ In regard to electronic microscopy, transmission electron microscopy (TEM) is one mode with sufficiently high resolution necessary for NP observation. ${ }^{49}$

Samples can be subjected to TEM or scanning EM (SEM), the first providing two-dimensional images and the latter producing three-dimensional images, but with lower resolution. ${ }^{16,49}$ Another imaging system is field-emission SEM, which provides a higher resolution in comparison 
to SEM. ${ }^{50,51}$ Studies like that conducted by Arulmozhi et al have used SEM for the characterization of NPs for oral cancer. They revealed spherical morphology and 30-120 nm diameters of the ellagic acid chitosan NPs they studied on KB oral carcinoma cells. ${ }^{51}$

For in vivo experiments, the main goal of imaging is to assess the proper biodistribution of the NPs in the tumor mass and to calculate the time needed for absorption in tumors and excretion. Optical in vivo imaging is also based on fluorophores, and in comparison with other in vivo imaging methods, has the advantage of real-time evaluation. ${ }^{52}$ All of these imaging techniques are summarized in Figure 2.

The process of developing novel therapeutic strategies is sustained by modern imaging approaches for evaluation of the dynamic transformation of therapeutic systems. Also, these imaging methods can be useful for a better understanding of action mechanisms for various nanodelivery systems tested in preclinical tests, not only for diagnostic purposes. ${ }^{53,54}$ Therefore, at present a wider range of imaging methods is available that can be implemented also in oral cancer, leading to improved diagnosis and an increased survival rate. ${ }^{53}$ These are represented by positron-emission tomography (PET), single-photon-emission computed tomography (SPECT)/ CT, magnetic resonance imaging, fluorescence and bioluminescence scanning, and photoacoustic methods. ${ }^{54}$ In PET imaging, NPs can be functionalized with an isotope, ${ }^{18} \mathrm{~F}$,

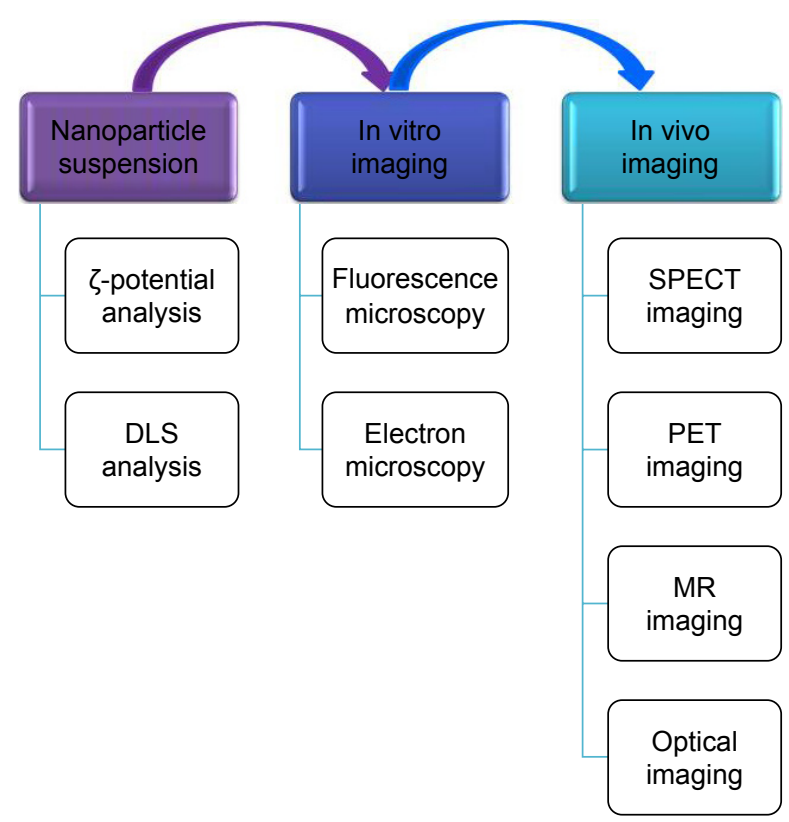

Figure $\mathbf{2}$ The main imaging techniques used for the characterizing of nanoparticles: when they are in suspension, following their internalization in cells in vitro imaging, or inside an organism in vivo imaging.

Abbreviations: SPECT, single-photon-emission computed tomography; DLS, dynamic light scattering; PET, positron-emission tomography; MR, magnetic resonance. which decays by positron emission, meaning that the atomic nucleus emits protons that will combine with electrons, ${ }^{55}$ while in SPECT $\gamma$-radiation is measured. ${ }^{56}$ NPs can be conjugated with ${ }^{125} \mathrm{I}$ and ${ }^{111} \mathrm{In}$, providing the option of this type of imaging. ${ }^{57}$ Under the influence of strong magnetism, the spin of the hydrogen protons inside an organism aligns with the magnetic field and can form images. ${ }^{58,59}$

The effects of polymeric micelle NPs loaded with cisdiamminedichloridoplatinum (CDDP) and conjugated with a cancer-specific targeting molecule, the peptide NR7, have been assessed. Size determined by DLS was $\sim 100 \mathrm{~nm}$ for the drug-loaded NPs and $\sim 135 \mathrm{~nm}$ with the addition of the targeting molecule. TEM was used for assessing the morphology of the NPs important to overall effectiveness and performance. This method revealed spherical morphology and uniform distribution. Loading the NPs with a fluorescent dye (rhodamine B) instead of CDDP allowed for the visualization and quantification of successful uptake of the NPs in the oral cancer cells and revealed a significantly higher uptake of the NPs containing the NR7 peptide. ${ }^{41,60}$

In in vivo studies, NP-treatment efficiency is assessed by histological examinations of H\&E-stained preparations of the sample under light microscopy ${ }^{61}$ or through more advanced methods. These include analysis of fluorescent or bioluminescent signals with an in vivo imaging system ${ }^{62}$ or Raman spectra differences through Raman spectroscopy. ${ }^{63}$

Gold nanorods (GNRs) are preferentially taken up by malignant cells, by using specific ligands for targeted delivery. The identification of residual cells during surgical resection by imaging methods exploiting NPs' physical properties for identification of tumor tissue and prevention of disease recurrence can be used in clinical application. One tested method is diffuse reflection evaluation in the case of functionalized NPs. ${ }^{64}$ This has been tested as an innovative system based on conjugating functionalized GNRs with EGFR as diagnostic tools, founded on the fact that EGFR is overexpressed in tumor tissue. This is a useful instrument for mapping tumor margins by quantification of anti-EGFR-GNRs. ${ }^{65}$ The physical properties of GNRs, like their reflectance, allow discrimination of normal tissue from tumors. ${ }^{64}$ Another important feature of GNRs is the unique scattering and absorption capacity evaluated using SEM. ${ }^{65}$ The technique needs to be standardized prior to its clinical application.

Developing a nanosystem with the appropriate biodistribution is important for the effectiveness of the treatment and for achieving the goal of lowering systemic toxicity. For the imaging of an orthotopic human model of cancer, like human head and neck $(\mathrm{HN})$ cancer FaDu3R cells, researchers have 
highlighted the accumulation of ${ }^{188}$ Re liposomes in a mouse model through 3-D reconstructed nano-SPECT/CT images by using a bioluminescent imaging system. ${ }^{62,66}$ Micro-PET is also a valuable visualization tool for the accumulation of NPs. Mahakian et al compared the accumulation of ${ }^{64} \mathrm{Cu}$ liposomes versus the standard radiotracer ${ }^{18} \mathrm{~F}$-FDG in a hamster buccal pouch model of oral cancer with PET imaging. They were able to determine superior accumulation of the liposomes over the standard radiotracer, demonstrating a potential use for liposomal therapy together with chemotherapeutics. ${ }^{67}$

By Atto-488 labeling of micelles containing elastin-like polypeptide, gastrin-releasing peptide, and a hydrophobic drug, the endocytosis of NPs was tracked through confocal imaging. ${ }^{68}$ With their high electron density, gold nanoparticles (GNPs) offer superior contrast in TEM images. Desmosome number and size in a 3-D coculture were measured with the help of immunogold labeling and TEM. More precisely, the samples were treated with antidesmosome primary antibodies to which $10 \mathrm{~nm}$ GNPs containing secondary antibodies were bound and visualized through TEM. The improvement of TEM images added a new layer of information about the invasiveness of human tongue cancer. ${ }^{69,70}$ Nonetheless, TEM has the disadvantage of being a static method that does not work with live cells/ tissue and has high costs and workload for sample preparation, though it does assure high accuracy of evaluation.

Upconversion NPs (UCNPs) are typically composed of nanocrystals with trivalent lanthanide ions that possess distinctive photoluminescence properties, which allow them to convert through multiphoton excitation electromagnetic radiation in the near-infrared region to shorter-wavelength light, in the visible or even ultraviolet spectrum. These NPs can be used both in vitro and in vivo, and are well suited for long-term observations. Among the reported advantages are the lack of autofluorescence background, persistent presence in the body, and low toxicity. ${ }^{71-73}$ Therefore, UCNPs could give rise to a new cancer cell-detection technique that uses dynamic imaging. For instance, a complex of UCNPs with GNPs targeting MMP2-recognizing peptides was employed for $\mathrm{HN}$ cancer-cell visualization in vitro. ${ }^{74}$ For improved properties, UCNPs can be surrounded by other structures, such as erythrocyte membrane. ${ }^{75}$

\section{Applications of nanotechnology- based drug-delivery systems in oral cancer therapy}

NPs can greatly reduce the side effects of anticancer drugs by augmenting their stability and regulating their targeted delivery. ${ }^{7}$ In oral cancer, a wide range of nanosystems (polymer-based nanocarriers, lipid-based nanocarriers, or metal-based nanocarriers) have been developed and evaluated on preclinical models. The most significant cell culturebased studies and also animal-based investigations in this field are summarized in Table 2.

\section{In vitro studies using polymer-based nanostructures}

The potential of $\mathrm{pH}$-sensitive poly(2-[methacryloyloxy] ethyl phosphorylcholine) (PDPA)-poly [2-diisopropylamino] ethyl methacrylate) (PMPC) polymersomes to encapsulate and deliver chemotherapeutic agents to tumor cells was investigated in an attempt at finding an enhanced combined anticancer therapy. Head and neck squamous cell carcinoma (HNSCC) cells internalized PMPC-PDPA polymersomes more quickly than normal ones. This may be attributable to cancer cells exhibiting a greater expression of class B scavenger receptors when compared to normal cells, taking into consideration that these receptors were shown to mediate cellular uptake of polymersomes. ${ }^{76}$ In addition, PMPC-PDPA polymersomes are able to encapsulate Dox and paclitaxel for either singular or combined delivery, and this drug-delivery system increased the cytotoxic effect of the chemotherapeutic agents. ${ }^{76}$

In OSCC therapy, polymeric nanomicelles loaded with a combination of Dox and an autophagy inhibitor, LY294002 (LY), were developed. This was done by conjugating Dox, a hydrophobic molecule with a $\mathrm{pH}$-sensitive, hydrophilic, hyperbranched polyacylhydrazone (HPAH). This complex assembles itself into nanomicelles in an aqueous solution, allowing LY to be loaded into the resulting HPAH-DOX micelles. ${ }^{77}$ In vitro experiments revealed that LY-loaded HPAH-DOX nanomicelles inhibited tumor-cell proliferation in a synergistic manner: LY is preferentially released in tumor cells, where it reduces autophagy capacity, rendering the tumor cells more sensitive to Dox, which is released afterward. ${ }^{77}$

Cisplatin is a major chemotherapeutic agent used for the treatment of HNSCC patients, but it also possesses a great number of side effects, such as nephrotoxicity. Endo et al chose this chemotherapeutic agent to test the safety and efficacy of loaded polymeric nanomicelles (NC-6004) in OSCC therapy. The results showed that although the in vitro antitumor activity of NC-6004 was less than that of free cisplatin, the antitumor effects in vivo were equal for both options. Moreover, the mice injected with NC-6004 sustained almost no renal injury, while those with cisplatin exhibited renal cell apoptosis. ${ }^{78}$

The biodegradable polymer poly(lactic-co-glycolic acid)polyethylene glycol (PEG) can be used for creating polymeric self-assembled NPs for the delivery of anticancer drugs. 
Table 2 Use of nanomaterial-based drug-delivery systems in oral cancer

\begin{tabular}{|c|c|c|c|c|}
\hline $\begin{array}{l}\text { Type of } \\
\text { study }\end{array}$ & $\begin{array}{l}\text { Type of } \\
\text { nanocarrier }\end{array}$ & Drug-delivery system & Study model & Reference(s) \\
\hline \multirow[t]{18}{*}{ In vitro } & $\begin{array}{l}\text { Polymer-based } \\
\text { nanocarriers }\end{array}$ & $\begin{array}{l}\text { PMPC-PDPA polymersomes loaded with doxorubicin and } \\
\text { paclitaxel }\end{array}$ & $\begin{array}{l}\text { Normal oral cells and HNSCC } \\
\text { cells }\end{array}$ & 76 \\
\hline & & $\begin{array}{l}\text { Polymeric nanomicelles to deliver an association of } \\
\text { doxorubicin and LY294002 (LY), an autophagy inhibitor }\end{array}$ & Oral cancer cells & 77 \\
\hline & & Cisplatin-loaded polymeric nanomicelles & Four OSCC cell lines & 78 \\
\hline & & $\begin{array}{l}\text { Polyamidoamine (PMAM) dendrimer mediated short hairpin } \\
\text { RNA (shRNA) }\end{array}$ & Oral cancer cell line & 81 \\
\hline & & Ellagic acid-encapsulated chitosan NPs & Human oral cancer cell line $(K B)$ & 51 \\
\hline & & CDDP-loaded PLGA-PEG NPs conjugated with NR7 peptide & HN6 cell line & 47 \\
\hline & & Chitosan NPs loaded with cupreous complexes & $\mathrm{KB}$ cells & 91 \\
\hline & & $\begin{array}{l}\text { PEG-PEI-Ce6 coupled with Wntl siRNA, targeting EMT, } \\
\text { invasion, and metastasis }\end{array}$ & $\mathrm{KB}$ cells & 32 \\
\hline & & Chitosan-coated PCL NPs loaded with curcumin & SCC9 human OSC cells & 46 \\
\hline & $\begin{array}{l}\text { Lipid-based } \\
\text { nanocarriers }\end{array}$ & Curcumin-lipid microemulsions & $\begin{array}{l}\text { OSCC cell lines (OSCC } 4 \text { and } \\
\text { OSCC25) }\end{array}$ & 82 \\
\hline & & $\begin{array}{l}\text { Transfection with HIFI decoy ODNs, using the HVJ- } \\
\text { liposome method }\end{array}$ & Oral cancer cell lines & 84 \\
\hline & & $\begin{array}{l}\text { Solid lipid NPs for delivering unstable and poorly water } \\
\text { soluble chemopreventive agents }\end{array}$ & Oral cancer cell lines & 85 \\
\hline & & $\begin{array}{l}\text { Nanoemulsion loaded with the proapoptotic lipophilic agent } \\
\text { genistein }\end{array}$ & $\begin{array}{l}\text { Human cancer cell lines SCC4 } \\
\text { and } \mathrm{FaDu}\end{array}$ & 83 \\
\hline & & Lipid-calcium-phosphate NPs loaded with HIFI $\alpha$ siRNA & SCC 4 or SAS cells & 100 \\
\hline & $\begin{array}{l}\text { Metal-based } \\
\text { nanocarriers }\end{array}$ & XAV939 conjugated with gold NPs & Human OSCC cell line (HSC3) & 86 \\
\hline & & Anti-HER2 nanobodies conjugated to gold-silica nanoshells & KB tumor cells & 87 \\
\hline & & $\mathrm{TiO}_{2} \mathrm{NPs}+$ high-intensity focused ultrasound & $\begin{array}{l}\text { Human oral squamous cell line } \\
\text { HSC-2 }\end{array}$ & 61 \\
\hline & & Dox-loaded silica-coated gold nanoflowers and PTT & Cal27 cells & 88 \\
\hline \multirow[t]{13}{*}{ In vivo } & $\begin{array}{l}\text { Polymer-based } \\
\text { nanocarriers }\end{array}$ & Naringenin-loaded polymeric NPs & $\begin{array}{l}\text { Hamster buccal pouch model } \\
\text { of OSCC }\end{array}$ & 63,89 \\
\hline & & Dox-Mtx NPs & Rat OSCC model & 90 \\
\hline & & Chitosan NPs loaded with cupreous complexes & $\begin{array}{l}\text { BALB/c nude mice with } K B \\
\text { tumors }\end{array}$ & 91 \\
\hline & $\begin{array}{l}\text { Lipid-based } \\
\text { nanocarriers }\end{array}$ & ${ }^{64} \mathrm{Cu}$ liposomes & $\begin{array}{l}\text { Hamster buccal pouch model of } \\
\text { oral dysplasia and SCC }\end{array}$ & 67 \\
\hline & & Boron delivery with liposomes for BNCT & Mouse model of OSCC & 92,97 \\
\hline & & & Hamster cheek-pouch model & \\
\hline & & Gene delivery in tumor tissue with Bubble liposomes & Mouse model & 98 \\
\hline & & ${ }^{188} \operatorname{Re}$ liposomes & $\begin{array}{l}\text { Orthotopic human HNSCC } \\
\text { tumor-bearing mice } \\
\text { (FaDu3R cells) }\end{array}$ & 62 \\
\hline & & Lipid-calcium-phosphate NPs with siVEGFA & $\begin{array}{l}\text { Human OSCC, SCC4, and SAS } \\
\text { xenograft }\end{array}$ & 99 \\
\hline & & Lipid-calcium-phosphate NPs loaded with HIFI $\alpha$ siRNA & Xenograft mouse & 100 \\
\hline & $\begin{array}{l}\text { Metal-based } \\
\text { nanocarriers }\end{array}$ & $\begin{array}{l}\text { Combined PDT and PTT with rose Bengal-conjugated gold } \\
\text { nanorods }\end{array}$ & $\begin{array}{l}\text { Hamster cheek pouch model of } \\
\text { OSCC }\end{array}$ & 101 \\
\hline & & $\mathrm{TiO}_{2} \mathrm{NPs}+$ high $=$ intensity focused ultrasound & HSC2 tumor mouse & 61 \\
\hline & & Cetuximab gold NPs & A43I mouse cells & 102 \\
\hline
\end{tabular}

Abbreviations: NPs, nanoparticles; PMPC, poly(2-[methacryloyloxy]ethyl phosphorylcholine); PDPA, poly(2-[diisopropylamino]ethyl methacrylate); HNSCC, head and neck squamous cell carcinoma; OSCC, oral squamous cell carcinoma; CDDP, cis-diamminedichloridoplatinum; PLGA, poly(lactic-co-glycolic acid); PEG, polyethylene glycol; PEI, polyethylenimine; EMT, epithelial-mesenchymal transition; PCL, polycaprolactone; ODNs, oligodeoxynucleotides; PTT, photothermal therapy; Dox, doxorubicin; Mtx, methotrexate; BNCT, boron neutron-capture therapy; PDT, photodynamic therapy.

This system was used for the targeted delivery of CDDP by using NR7 peptide in HN6 cells. This resulted in higher cellular uptake and superior apoptosis effects on oral cancer cells. ${ }^{47}$
Natural compounds are another valid option for mouth cancer treatment, but they exhibit poor bioavailability. ${ }^{79,80}$ The answer to this problem may come from nanocarriers. For instance, ellagic acid and curcumin, two natural phenolic 
antioxidants with proapoptotic effects in cancerous cells, were loaded on a chitosan biopolymeric nanocarrier. In the case of the KB cell line, a cross-contaminated cell line with HeLa cells, the nanocarrier enhanced the effects of ellagic acid, and in SCC9 cells the NPs showed mucoadhesive properties, interacting with the glycoprotein mucin and leading to increased apoptosis. ${ }^{46,51}$

One step further may be the nanodelivery of RNA. The HTERT gene was successfully silenced by dendrimerdelivered shRNA in vitro, resulting in cell death and growth inhibition; meanwhile, in a xenograft mouse model it reduced tumor growth. Therefore, NP-delivery systems can likewise be used for the delivery of RNA interference, also called siRNA. ${ }^{81}$ PEG-polyethyleneimine-chlorin e6 delivery system was used for Wnt1 siRNA transfection on KB cells. Based on functional studies, it was revealed that inhibition of the Wnt- $\beta$-catenin signaling pathway inhibited expression levels of WNT1, CTNNB1, and VIM, essential genes involved in the regulation of epithelial-mesenchymal transition, an event that sustains the invasion and migration of tumor cells. ${ }^{32}$

\section{In vitro studies using lipid-based nanostructures}

Natural anticancer agents can also be delivered with the use of NPs. Lipid-based nanocarriers, as well as their types of nanodelivery systems, can transport both hydrophilic and hydrophobic compounds and are able to be functionalized with targeting molecules (Figure 3). Natural compounds have well-known beneficial but limited effects. As follows, curcumin lipid microemulsions in combination with low-frequency ultrasound were tested on two oral cancer cell lines: OSCC4 and OSCC25. The cytotoxic properties of these microemulsions were greatly amplified by the addition of ultrasound, proving that this synergy may be effective in oral cancer treatment. ${ }^{82}$ Nanoemulsions loaded with genistein developed in the form of a lozenge also manifested strong in vitro cytotoxicity in the case of the two cancer cell lines SCC4 and FaDu. ${ }^{83}$

Imai et al transfected HIF1 decoy oligodeoxynucleotides into OSCC cells using the hemagglutinating virus of Japanliposome method. The results showed that the transfection of HIF1-decoy oligodeoxynucleotides was able to repress the hypoxia-mediated expression of VEGF, which plays a pivotal role in tumor angiogenesis. ${ }^{84}$ Human OSCC cell lines internalized solid lipid NPs of unstable and poorly water-soluble chemopreventive agents better than by bolus administration. Additionally, given the presence of the NPs in the proliferating basal layer cells, this system might be of great aid in local delivery of chemotherapeutic agents. ${ }^{85}$

\section{In vitro studies using metal-based nanostructures}

Metal-based nanostructures are another auspicious nanocarrier class whose place in OSCC therapy has been investigated. XAV939 is a small-molecule inhibitor that was reported to

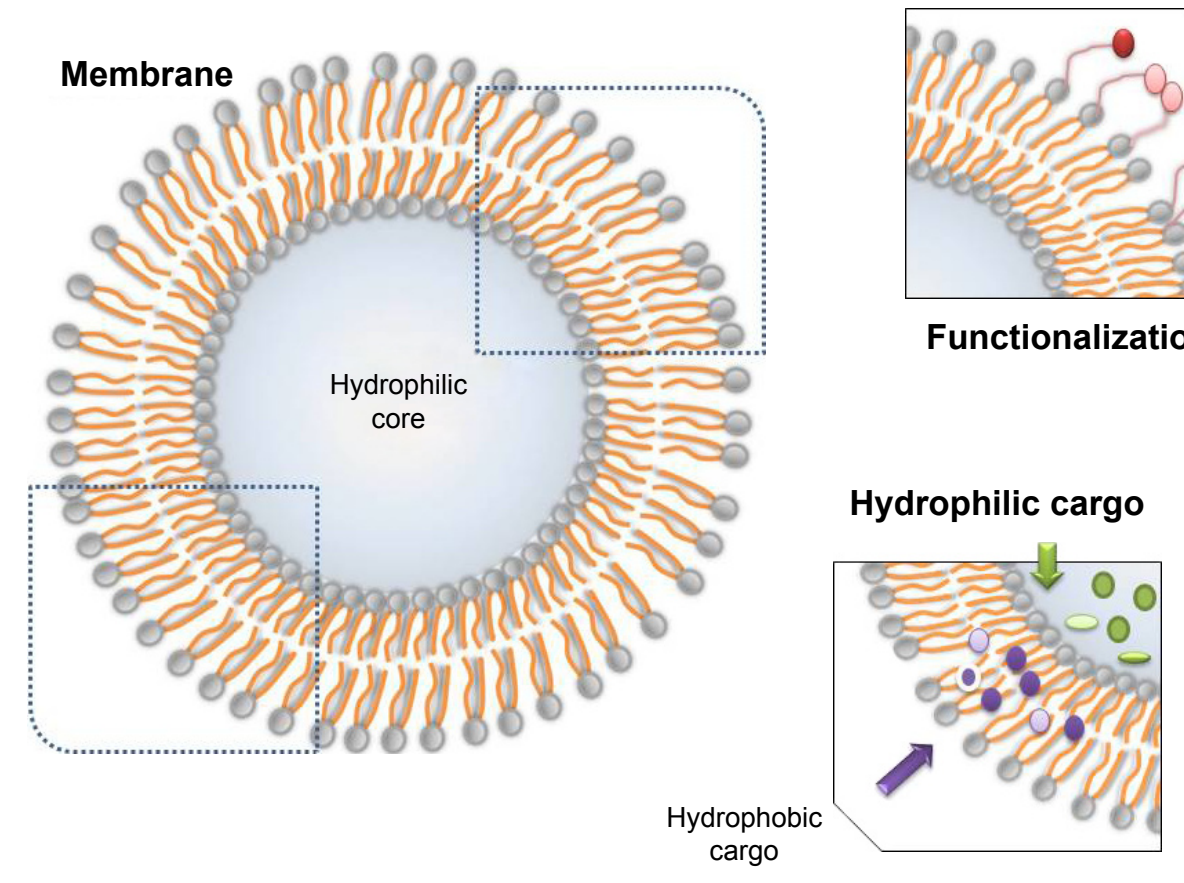

Figure 3 Localization and types of cargo in a liposome.

Notes: Hydrophylic cargo is carried inside the core and the hydrophobic cargo within the membrane. The membrane can be conjugated with molecules for functionalization. 
modulate the Wnt pathway with consequent stabilization of Axin levels in the cytoplasm. Loading XAV939 on gold nanospheres increased its therapeutic potency in the HSC3 cell line about 100 times over the free form ${ }^{86}$ An alternative treatment for OSCC is represented by the use of anti-HER2 nanobodies conjugated to gold-silica nanoshells and subsequently applied as a photothermal therapy (PTT). It was revealed that while KB HER-positive cells underwent significant cell death, HER-negative HeLa S3 cells remained unharmed, thus confirming that the treatment provides great advantages concerning OSCC.$^{87}$ Dox-loaded nanocarriers in the form of silica-coated gold nanoflowers that were used in combination with near-infrared PTT in human tongue SCC Cal27 cells induced rapid drug release, demonstrating the synergistic effect of this strategy. ${ }^{88}$

\section{In vivo studies using polymer-based nanostructures}

Polymeric NPs have been used for natural chemopreventive compounds, such as naringenin delivery. On a hamster buccal pouch model of OSCC, it was demonstrated that NP drug delivery diminished tumor development and reduced oral lesions to a much higher degree than the free form. ${ }^{89}$ In the same in vivo model, by Fourier-transform Raman spectroscopy, it was reported that the antitumor effect of naringenin-loaded NPs was greater than that of the free form in renormalizing biochemical status, hence providing a future effective chemopreventive strategy for OSCC. ${ }^{63}$

In vivo, the efficacy of NPs loaded with Dox alone or in combination with methotrexate was assessed in OSCC rats. DOX-methotrexate NP systems, in addition to promoting apoptosis, were able to decrease expression levels significantly for VEGFC, a lymph-angiogenesis-promoting factor, whereas Dox did not have this effect. Since VEGFC is one of the main factors accounting for OSCC lymph-node metastasis, the future prospects are on the rise. ${ }^{90}$ Promising results were obtained in a mouse model of $\mathrm{KB}$ tumor, where chitosan NPs loaded with cupreous complexes were adopted. The biocompatible chitosan layer temporarily lowered the toxicity of the cupreous complex, and by gradual degradation allowed a steady release of toxic complexes. ${ }^{91}$

\section{In vitro studies using lipid-based nanostructures}

NP-delivery systems can be beneficial not only for OSCC chemoprevention and therapy but also for its early detection and staging. A dimethylbenzanthracene-induced hamster buccal pouch model of oral dysplasia and SCC revealed that ${ }^{18} \mathrm{~F}$-FDG had low sensitivity during early stages; meanwhile, ${ }^{64} \mathrm{Cu}$ liposomes accumulated in all OSCC stages, thus confirming their superior sensitivity. As a radiotracer, ${ }^{64} \mathrm{Cu}$ liposomes are able to augment HNSCC visualization and early detection. ${ }^{67}$

Boron neutron-capture therapy is a dual cancer-therapy option that combines selective buildup of tumor-targeting compounds containing boron and neutron irradiation. Consequently, tumor tissue is selectively targeted for irradiation. ${ }^{92}$ This treatment modality has been studied in relation to oral cancer treatment, especially for the recurrent subsets, and was found to be successful in both in vitro and in vivo experiments. ${ }^{93-95}$

Recently, scientists have been focusing on improving boron neutron-capture therapy with the help of nanocarriers, led by the wish of developing a new targeted cancer therapy. The results in a mouse model of OSCC showed that boronenriched liposomes had better distribution in cancer cells and a hamster cheek-pouch model, and tumor growth was present in only $13 \%$ of the treated tumors after a 16 week period when compared to untreated animals or ones treated only with beam radiation. ${ }^{96,97}$ By associating Bubble liposomes with ultrasound, plasmid DNA was very effectively introduced into tongue tissue, which may prove to be another promising approach for gene delivery as a treatment option for tongue cancer patients. ${ }^{98}$ Radiopharmaceuticals are an alternative to radiotherapy. ${ }^{188} \mathrm{Re}$-embedded PEGylated liposomes have been found to repress xenograft human HNSCC tumors effectively, maybe through the induction of tumorsuppressive signaling pathways, since LET7 expression was enhanced posttreatment. ${ }^{62}$

siRNA (siVEGFA) was loaded onto lipid-calciumphosphate NPs and combined with photodynamic therapy (PDT), in order to decrease tumor proliferation and promote cellular apoptosis in HNSCC. However, PDT has a hidden facet that promotes hypoxic conditions and leads to overexpression of angiogenic markers like VEGFA. ${ }^{99}$ Anisamidetargeted lipid-calcium-phosphate NPs loaded with HIF1 $\alpha$ siRNA in combination with photosan-mediated PDT showed tumor-cell-killing effects in SCC4 and SAS cells. ${ }^{100}$

\section{In vitro studies using metal-based nanostructures}

Another future treatment approach for oral cancer could be a combined PDT-PTT therapy using rose Bengal-conjugated GNRs. The combined PDT/PTT with rose Bengal GNRs was more effective than PDT or PTT alone on a hamster cheek-pouch model of OSCC. One of the major advantages 
of this system is that rose Bengal is specific for oral cells, hence promoting the accumulation of GNRs in the cancerous cells. ${ }^{101}$

Photocatalytic titanium dioxide NPs together with highintensity focused ultrasound seems to be another valid option, due to the strong oxidizing activity of titanium dioxide, its stability, lack of chemical reactivity in biological systems, and the potential of high-intensity focused ultrasound as an efficient activation method. Indeed, on the human SCC cell line HSC2 and an in vivo mouse model, the combination enhanced the cytotoxicity of the titanium dioxide in vitro and increased transfection in vivo. ${ }^{61}$ In addition, GNPs can be used as radiosensitizing agents that lead to improved survival and decreased tumor size, due to elevated radiation absorption. Encouraging results were achieved with cetuximab coated with GNPs, used in an in vivo model undergoing radiation treatment. ${ }^{102}$

An important issue is the mechanism of elimination of this type of nanostructure and the avoidance of their accumulation in the internal organs, this being the main issue that limits the utilization of nanostructures in clinics, as we observed in our previous study. ${ }^{103,104}$ An accurate verification of biologically active properties in proper animal models will sustain the next level of this research in clinical trials.

\section{Clinical trials}

The surface-active agent needed for conventional paclitaxel administration can trigger severe allergic reactions. Paclitaxel was loaded into human albumin NPs and administered intra-arterially to 23 untreated patients with advanced tongue SCC. The conclusion was that this method is both effective and reproducible. Following this, 60 patients who suffered from stage T3/4 oral cancer participated in Phase II of the trial, where the positive effects were reaffirmed, providing an encouraging new approach for preliminary chemotherapy in tongue SCC. ${ }^{105-107}$ Another Phase I trial investigated the use of NP albumin-bound paclitaxel (Abraxane) in designing a regimen combining cetuximab-loaded NPs with radiation therapy. A total of 25 patients with stage III-IVB HNSCC took the proposed treatment, and the researchers determined an optimum dose of NPs that could be further investigated and administered to patients already undergoing cetuximab and radiation therapy. ${ }^{108}$

Currently, there is also an active Phase II clinical trial on stage III/IV HN cancer that focuses on the effectiveness of chemotherapy induction and the formulation of paclitaxel albumin NPs in combination with cisplatin, fluorouracil, and chemoradiation (ClinicalTrials.gov NCT01566435).
More trials are in development or in the recruitment phase. Another interesting trial in the recruitment phase will investigate the use of NP-coated NBTXR3, a radioenhancer, followed by radiotherapy in patients with advanced oral cancer (ClinicalTrials.gov NCT01946867). Albuminbound paclitaxel NPs will again be used in a future Phase I clinical trial of HN cancer patients who are currently being treated with carboplatin and radiation (ClinicalTrials.gov NCT01847326). The paclitaxel albumin-stabilized NP formulation together with carboplatin is the subject of another trial in the recruitment phase on patients with oral stage II carcinoma or papillomavirus-related oropharyngeal cancer (ClinicalTrials.gov NCT02258659).

\section{Conclusion and future perspectives}

Oral cancer is one of the most common cancers worldwide in both men and women. Conventional treatment can raise issues and complications that could be addressed by alternative treatment strategies. One such strategy is the use of nanodelivery systems that could target malignant cells with improved efficiency and less damage to healthy cells; these data being summarized in Figure 4. As such, this novel approach has been tried in in vitro and in vivo models and even in clinical trials, with promising outlooks for the future. Various forms of delivery have been studied as treatment options for this type of cancer, including polymeric, lipid, and metallic-based forms. These nanosystems contain different types of cargo, like chemotherapeutics (Dox, paclitaxel, or cisplatin) or natural compounds (that have important anticancer properties, like curcumin, genistein, or naringenin). siRNA-based therapy can also be facilitated by these systems by temper-activated oncogenic pathways, as exemplified through such molecules as VEGFA siRNA or HIF $1 \alpha$ siRNA delivery, targeting angiogenesis of hypoxia.

Another important issue that needs to be solved in all cancer types, including oral cancer, is that related to novel diagnostic approaches and monitoring of therapy response. Some types of cargo besides these have been proven effective, and there are numerous strategies being applied for treatment of oral cancer with these novel nanosystems. These strategies apply the use of ultrasounds, PTD, or PTT.

Overall, nanotechnology-based drug delivery is an attractive form of cure that has great therapeutic potential in the case of oral cancer patients. Future studies and the development of more clinical trials will lead to the use of nanosystems as active treatment options for patients. Among the therapeutic methods evaluated, the developing of efficient siRNA-based delivery will provide an improved 


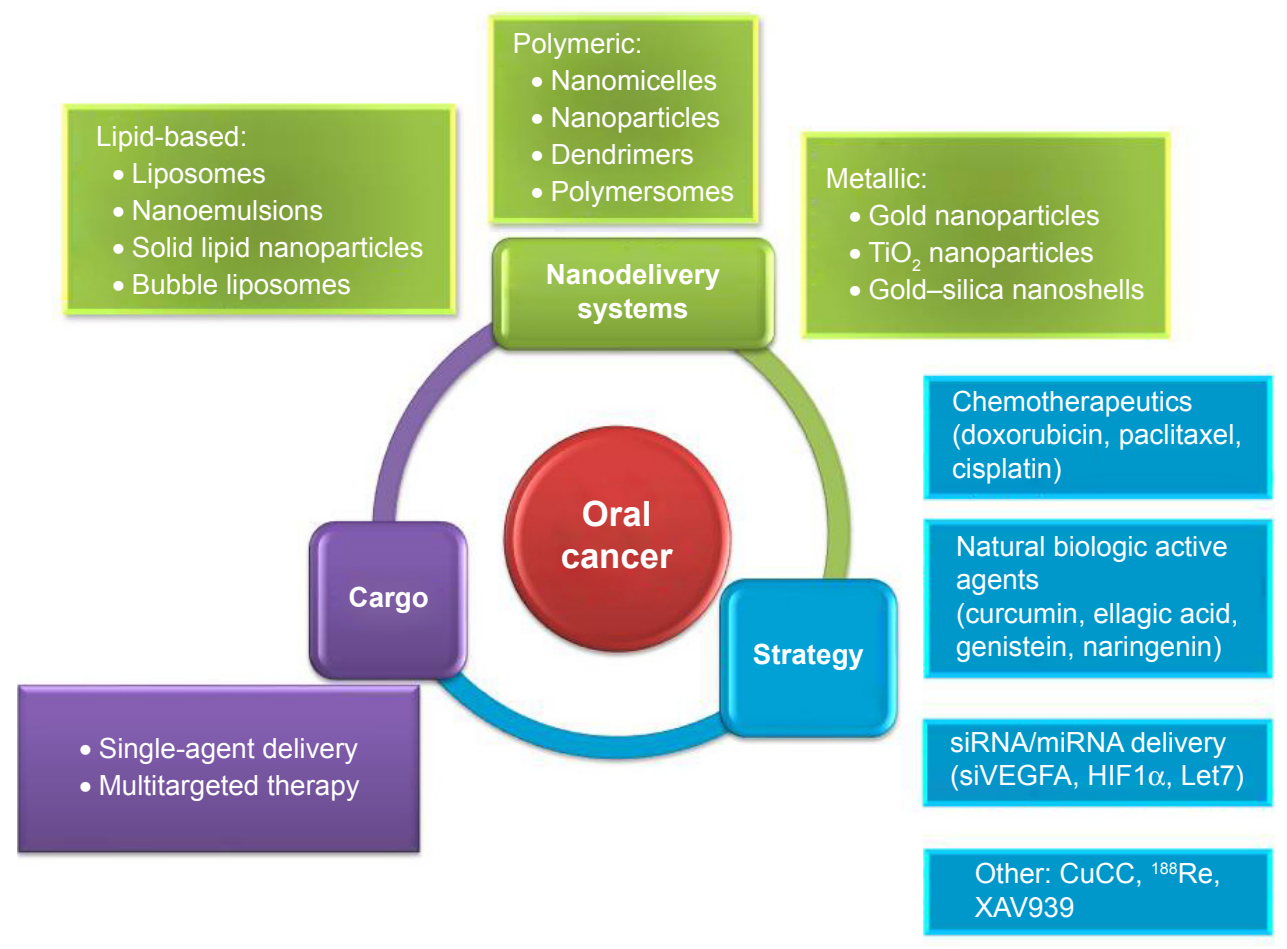

Figure 4 Nanodelivery systems used in oral cancer.

Abbreviation: CuCC, cupreous complex-loaded chitosan.

strategy, centered on the restoration of the altered molecular target and by preventing the activation of the mechanism responsible for resistance to therapy. In parallel with efficient cargoes and delivery systems, all this needs to be sustained by tracking approaches, this remaining as the major issue of the biomedical community. At the forefront of future prospects, a new frontier emerges in which nanodelivery and imaging systems are in accordance with the most upto-date findings in personalized medicine, and will convey to cancer patients an individualized cargo composed of a specific gene-silencer repertoire that could be associated or not with artificial or natural anticancer compounds, leading to increased survival rates, even in the case of advanced stages or those with an unfavorable prognosis. It is expected that there will be an increase in NP-based therapies not only for oral cancer but also for other types of cancer, acting mainly by reducing aspecific cell toxicity and by developing targeted therapies. The success of these nanodelivery systems is expected when the research is performed in a multidisciplinary environment.

\section{Acknowledgments}

This study was supported by an internal grant (4944/6/ 08.03.2016) from Iuliu Hatieganu University of Medicine and Pharmacy, entitled "Identification of methylation profile for the genes related with the oral squamous cancer". Dr Mehterov's work was in part supported by Project HO-18/2014, funded by the Medical University of Plovdiv.

\section{Disclosure}

The authors report no conflicts of interest in this work.

\section{References}

1. Siegel RL, Miller KD, Jemal A. Cancer Statistics, 2017. CA Cancer J Clin. 2017;67(1):7-30.

2. Marron M, Boffetta P, Zhang ZF, et al. Cessation of alcohol drinking, tobacco smoking and the reversal of head and neck cancer risk. Int $J$ Epidemiol. 2010;39(1):182-196.

3. Toporcov TN, Znaor A, Zhang ZF, et al. Risk factors for head and neck cancer in young adults: a pooled analysis in the INHANCE consortium. Int J Epidemiol. 2015;44(1):169-185.

4. Huang SH, O'Sullivan B. Oral cancer: current role of radiotherapy and chemotherapy. Med Oral Patol Oral Cir Bucal. 2013;18(2): e233-e240.

5. Rivera C. Essentials of oral cancer. Int J Clin Exp Pathol. 2015;8(9): 11884-11894.

6. Irimie AI, Braicu C, Cojocneanu-Petric R, Berindan-Neagoe I, Campian RS. Novel technologies for oral squamous carcinoma biomarkers in diagnostics and prognostics. Acta Odontol Scand. 2015;73(3):161-168.

7. Calixto G, Bernegossi J, Fonseca-Santos B, Chorilli M. Nanotechnologybased drug delivery systems for treatment of oral cancer: a review. Int J Nanomedicine. 2014;9:3719-3735.

8. Bertrand N, Wu J, Xu X, Kamaly N, Farokhzad OC. Cancer nanotechnology: the impact of passive and active targeting in the era of modern cancer biology. Adv Drug Deliv Rev. 2014;66:2-25.

9. Jain RK, Stylianopoulos T. Delivering nanomedicine to solid tumors. Nat Rev Clin Oncol. 2010;7(11):653-664. 
10. Li Y, Wang J, Wientjes MG, Au JL. Delivery of nanomedicines to extracellular and intracellular compartments of a solid tumor. Adv Drug Deliv Rev. 2012;64(1):29-39.

11. Braicu C, Cojocneanu-Petric R, Chira S, et al. Clinical and pathological implications of miRNA in bladder cancer. Int J Nanomedicine. 2015;10: 791-800.

12. Agostinelli E, Vianello F, Magliulo G, Thomas T, Thomas TJ. Nanoparticle strategies for cancer therapeutics: Nucleic acids, polyamines, bovine serum amine oxidase and iron oxide nanoparticles (review). Int J Oncol. 2015;46(1):5-16.

13. Cho K, Wang X, Nie S, Chen ZG, Shin DM. Therapeutic nanoparticles for drug delivery in cancer. Clin Cancer Res. 2008;14(5):1310-1316.

14. Suri SS, Fenniri H, Singh B. Nanotechnology-based drug delivery systems. J Occup Med Toxicol. 2007;2:16.

15. Devalapally H, Chakilam A, Amiji MM. Role of nanotechnology in pharmaceutical product development. J Pharm Sci. 2007;96(10): 2547-2565.

16. Mishra B, Chaurasia S. Design of novel chemotherapeutic delivery systems for colon cancer therapy based on oral polymeric nanoparticles. Ther Deliv. 2017;8(1):29-47.

17. Arachchige MC, Reshetnyak YK, Andreev OA. Advanced targeted nanomedicine. J Biotechnol. 2015;202:88-97.

18. Anselmo AC, Mitragotri S. An overview of clinical and commercial impact of drug delivery systems. J Control Release. 2014;190:15-28.

19. Davis ME, Chen ZG, Shin DM. Nanoparticle therapeutics: an emerging treatment modality for cancer. Nat Rev Drug Discov. 2008;7(9): 771-782.

20. Oh N, Park JH. Endocytosis and exocytosis of nanoparticles in mammalian cells. Int J Nanomedicine. 2014;9 Suppl 1:51-63.

21. Yang Q, Xu E, Dai J, et al. A novel long noncoding RNA AK001796 acts as an oncogene and is involved in cell growth inhibition by resveratrol in lung cancer. Toxicol App Pharmacol. 2015;285(2): 79-88.

22. Rejman J, Oberle V, Zuhorn IS, Hoekstra D. Size-dependent internalization of particles via the pathways of clathrin- and caveolae-mediated endocytosis. Biochem J. 2004;377(Pt 1):159-169.

23. Bathori G, Cervenak L, Karadi I. Caveolae: an alternative endocytotic pathway for targeted drug delivery. Crit Rev Ther Drug Carrier Syst. 2004;21(2):67-95.

24. Georgieva JV, Kalicharan D, Couraud PO, et al. Surface characteristics of nanoparticles determine their intracellular fate in and processing by human blood-brain barrier endothelial cells in vitro. Mol Ther. 2011; 19(2):318-325.

25. Iversen TG, Skotland T, Sandvig K. Endocytosis and intracellular transport of nanoparticles: present knowledge and need for future studies. Nano Today. 2011;6(2):176-185.

26. Kumari S, Mg S, Mayor S. Endocytosis unplugged: multiple ways to enter the cell. Cell Res. 2010;20(3):256-275.

27. Zhang S, Gao H, Bao G. Physical principles of nanoparticle cellular endocytosis. ACS Nano. 2015;9(9):8655-8671.

28. Hillaireau H, Couvreur P. Nanocarriers' entry into the cell: relevance to drug delivery. Cell Mol Life Sci. 2009;66(17):2873-2896.

29. Torchilin VP. Tat peptide-mediated intracellular delivery of pharmaceutical nanocarriers. Adv Drug Deliv Rev. 2008;60(4-5):548-558.

30. Rapoport M, Lorberboum-Galski H. TAT-based drug delivery system: new directions in protein delivery for new hopes? Expert Opin Drug Deliv. 2009;6(5):453-463.

31. Kunisawa J, Masuda T, Katayama K, et al. Fusogenic liposome delivers encapsulated nanoparticles for cytosolic controlled gene release. J Control Release. 2005;105(3):344-353.

32. Ma C, Shi L, Huang Y, et al. Nanoparticle delivery of Wnt-1 siRNA enhances photodynamic therapy by inhibiting epithelial-mesenchymal transition for oral cancer. Biomater Sci. 2017;5(3):494-501.

33. Akbarzadeh A, Rezaei-Sadabady R, Davaran S, et al. Liposome: classification, preparation, and applications. Nanoscale Res Lett. 2013; $8(1): 102$.
34. Szebeni J. Complement activation-related pseudoallergy: a new class of druginduced acute immune toxicity. Toxicology. 2005;216(2-3):106-121.

35. Kontermann RE. Immunoliposomes for cancer therapy. Curr Opin Mol Ther. 2006;8(1):39-45.

36. Samad A, Sultana Y, Aqil M. Liposomal drug delivery systems: an update review. Curr Drug Deliv. 2007;4(4):297-305.

37. Perez-Herrero E, Fernandez-Medarde A. Advanced targeted therapies in cancer: drug nanocarriers, the future of chemotherapy. Eur J Pharm Biopharm. 2015;93:52-79.

38. Torchilin VP. Micellar nanocarriers: pharmaceutical perspectives. Pharm Res. 2007;24(1):1-16.

39. Lu Y, Park K. Polymeric micelles and alternative nanonized delivery vehicles for poorly soluble drugs. Int J Pharm. 2013;453(1):198-214.

40. Wolinsky JB, Grinstaff MW. Therapeutic and diagnostic applications of dendrimers for cancer treatment. Adv Drug Deliv Rev. 2008;60(9): 1037-1055

41. Wang X, Wang Y, Chen ZG, Shin DM. Advances of cancer therapy by nanotechnology. Cancer Res Treat. 2009;41(1):1-11.

42. Rao JP, Geckeler KE. Polymer nanoparticles: preparation techniques and size-control parameters. Prog Polym Sci. 2011;36(7):887-913.

43. Peer D, Karp JM, Hong S, Farokhzad OC, Margalit R, Langer R. Nanocarriers as an emerging platform for cancer therapy. Nat Nanotechnol. 2007;2(12):751-760.

44. Li C, Ge X, Wang L. Construction and comparison of different nanocarriers for co-delivery of cisplatin and curcumin: a synergistic combination nanotherapy for cervical cancer. Biomed Pharmacother. 2017;86: 628-636.

45. Ajorlou E, Khosroushahi AY. Trends on polymer- and lipid-based nanostructures for parenteral drug delivery to tumors. Cancer Chemother Pharmacol. 2017;79(2):251-265.

46. Mazzarino L, Loch-Neckel G, Bubniak LS, et al. Curcumin-loaded chitosan-coated nanoparticles as a new approach for the local treatment of oral cavity cancer. J Nanosci Nanotechnol. 2015;15(1):781-791.

47. Wang ZQ, Liu K, Huo ZJ, et al. A cell-targeted chemotherapeutic nanomedicine strategy for oral squamous cell carcinoma therapy. J Nanobiotechnology. 2015;13:63.

48. Wolfbeis OS. An overview of nanoparticles commonly used in fluorescent bioimaging. Chem Soc Rev. 2015;44(14):4743-4768.

49. Muhlfeld C, Rothen-Rutishauser B, Vanhecke D, Blank F, Gehr P, Ochs M. Visualization and quantitative analysis of nanoparticles in the respiratory tract by transmission electron microscopy. Part Fibre Toxicol. 2007;4:11.

50. Yao H, Kimura K. Field emission scanning electron microscopy for structural characterization of 3D gold nanoparticle superlattices. In: Méndez-Vilas A, Díaz J, editors. Modern Research and Educational Topics in Microscopy. Badajoz, Spain: Formatex; 2007:568-575.

51. Arulmozhi V, Pandian K, Mirunalini S. Ellagic acid encapsulated chitosan nanoparticles for drug delivery system in human oral cancer cell line (KB). Colloids Surf B Biointerfaces. 2013;110:313-320.

52. England CG, Hernandez R, Eddine SB, Cai W. Molecular imaging of pancreatic cancer with antibodies. Mol Pharm. 2016;13(1):8-24.

53. Saadatpour Z, Rezaei A, Ebrahimnejad H, et al. Imaging techniques: new avenues in cancer gene and cell therapy. Cancer Gene Ther. 2017; 24(1):1-5

54. Xin Y, Liu T, Yang C. Development of PLGA-lipid nanoparticles with covalently conjugated indocyanine green as a versatile nanoplatform for tumor-targeted imaging and drug delivery. Int J Nanomedicine. 2016;11:5807-5821.

55. Devaraj NK, Keliher EJ, Thurber GM, Nahrendorf M, Weissleder R. $18 \mathrm{~F}$ labeled nanoparticles for in vivo PET-CT imaging. Bioconjug Chem. 2009;20(2):397-401.

56. de Jong M, Essers J, van Weerden WM. Imaging preclinical tumour models: improving translational power. Nat Rev Cancer. 2014;14(7):481-493.

57. Black KC, Akers WJ, Sudlow G, Xu B, Laforest R, Achilefu S. Dualradiolabeled nanoparticle SPECT probes for bioimaging. Nanoscale. 2015;7(2):440-444. 
58. Morelli JN, Runge VM, Ai F, et al. An image-based approach to understanding the physics of MR artifacts. Radiographics. 2011;31(3): 849-866.

59. Pooley RA. AAPM/RSNA physics tutorial for residents: fundamental physics of MR imaging. Radiographics. 2005;25(4):1087-1099.

60. Vigarios E, Epstein JB, Sibaud V. Oral mucosal changes induced by anticancer targeted therapies and immune checkpoint inhibitors. Support Care Cancer. 2017;25(5):1713-1739.

61. Nejad SM, Takahashi H, Hosseini H, et al. Acute effects of sono-activated photocatalytic titanium dioxide nanoparticles on oral squamous cell carcinoma. Ultrason Sonochem. 2016;32:95-101.

62. Lin LT, Chang CY, Chang CH, et al. Involvement of Let-7 microRNA for the therapeutic effects of rhenium-188-embedded liposomal nanoparticles on orthotopic human head and neck cancer model. Oncotarget. 2016;7(40):65782-65796.

63. Krishnakumar N, Sulfikkarali NK, Manoharan S, Venkatachalam P. Raman spectroscopic investigation of the chemopreventive response of naringenin and its nanoparticles in DMBA-induced oral carcinogenesis. Spectrochim Acta A Mol Biomol Spectrosc. 2013;115:648-653.

64. Hirshberg A, Allon I, Novikov I, Ankri R, Ashkenazy A, Fixler D. Gold nanorods reflectance discriminate benign from malignant oral lesions. Nanomedicine. 2017;13(4):1333-1339.

65. Ankri R, Ashkenazy A, Milstein Y, et al. Gold nanorods based air scanning electron microscopy and diffusion reflection imaging for mapping tumor margins in squamous cell carcinoma. ACS Nano. 2016; 10(2):2349-2356.

66. Santoro A, Papagerakis S, Serpico R, Guida A, Muzio L, Bufo P. Epigenetic profiling of oral cancer. In: Ogbureke KU, editor. Oral Cancer. Rijeka, Croatia: InTech; 2012:297-326.

67. Mahakian LM, Farwell DG, Zhang H, et al. Comparison of PET imaging with $64 \mathrm{Cu}$-liposomes and 18F-FDG in the 7,12-dimethylbenz[a]anthracene (DMBA)-induced hamster buccal pouch model of oral dysplasia and squamous cell carcinoma. Mol Imaging Biol. 2014;16(2):284-292.

68. Zhang W, Garg S, Eldi P, et al. Targeting prostate cancer cells with genetically engineered polypeptide-based micelles displaying gastrinreleasing peptide. Int J Pharm. 2016;513(1-2):270-279.

69. Sawant S, Dongre H, Singh AK, et al. Establishment of 3D coculture models from different stages of human tongue tumorigenesis: utility in understanding neoplastic progression. PloS One. 2016; 11(8):e0160615.

70. Guggenheim EJ, Khan A, Pike J, Chang L, Lynch I, Rappoport JZ. Comparison of confocal and super-resolution reflectance imaging of metal oxide nanoparticles. PloS One. 2016;11(10):e0159980.

71. Chatterjee DK, Rufaihah AJ, Zhang Y. Upconversion fluorescence imaging of cells and small animals using lanthanide doped nanocrystals. Biomaterials. 2008;29(7):937-943.

72. Wang C, Cheng L, Liu Z. Drug delivery with upconversion nanoparticles for multi-functional targeted cancer cell imaging and therapy. Biomaterials. 2011;32(4):1110-1120.

73. Chen G, Qiu H, Prasad PN, Chen X. Upconversion nanoparticles: design, nanochemistry, and applications in theranostics. Chem Rev. 2014; 114(10):5161-5214.

74. Chan YC, Chen CW, Chan MH, et al. MMP2-sensing up-conversion nanoparticle for fluorescence biosensing in head and neck cancer cells. Biosens Bioelectro. 2016;80:131-139.

75. Rao L, Meng QF, Bu LL, et al. Erythrocyte membrane-coated upconversion nanoparticles with minimal protein adsorption for enhanced tumor imaging. ACS Appl Mater Interfaces. 2017;9(3):2159-2168.

76. Colley HE, Hearnden V, Avila-Olias M, et al. Polymersome-mediated delivery of combination anticancer therapy to head and neck cancer cells: 2D and 3D in vitro evaluation. Mol Pharm. 2014;11(4): 1176-1188.

77. Saiyin W, Wang D, Li L, et al. Sequential release of autophagy inhibitor and chemotherapeutic drug with polymeric delivery system for oral squamous cell carcinoma therapy. Mol Pharm. 2014;11(5): $1662-1675$.
78. Endo K, Ueno T, Kondo S, et al. Tumor-targeted chemotherapy with the nanopolymer-based drug NC-6004 for oral squamous cell carcinoma. Cancer Sci. 2013;104(3):369-374.

79. Braicu C, Gherman C. Epigallocatechin gallate induce cell death and apoptosis in triple negative breast cancer cells Hs578T. J Drug Target. Epub 2012 Nov 19.

80. Braicu C, Gherman CD, Irimie A, Berindan-Neagoe I. Epigallocatechin-3Gallate (EGCG) inhibits cell proliferation and migratory behaviour of triple negative breast cancer cells. J Nanosci Nanotechnol. 2013;13(1): 632-637.

81. Liu X, Huang H, Wang J, et al. Dendrimers-delivered short hairpin RNA targeting hTERT inhibits oral cancer cell growth in vitro and in vivo. Biochem Pharmacol. 2011;82(1):17-23.

82. Lin HY, Thomas JL, Chen HW, Shen CM, Yang WJ, Lee MH. In vitro suppression of oral squamous cell carcinoma growth by ultrasoundmediated delivery of curcumin microemulsions. Int J Nanomedicine. 2012;7:941-951

83. Gavin A, Pham JT, Wang D, Brownlow B, Elbayoumi TA. Layered nanoemulsions as mucoadhesive buccal systems for controlled delivery of oral cancer therapeutics. Int J Nanomedicine. 2015;10: 1569-1584.

84. Imai M, Ishibashi H, Nariai Y, et al. Transfection of hypoxia-inducible factor-1 decoy oligodeoxynucleotides suppresses expression of vascular endothelial growth factor in oral squamous cell carcinoma cells J Oral Pathol Med. 2012;41(9):675-681.

85. Holpuch AS, Hummel GJ, Tong M, et al. Nanoparticles for local drug delivery to the oral mucosa: proof of principle studies. Pharm Res. 2010;27(7):1224-1236.

86. Afifi MM, Austin LA, Mackey MA, El-Sayed MA. XAV939: from a small inhibitor to a potent drug bioconjugate when delivered by gold nanoparticles. Bioconjug Chem. 2014;25(2):207-215.

87. Fekrazad R, Hakimiha N, Farokhi E, et al. Treatment of oral squamous cell carcinoma using anti-HER2 immunonanoshells. Int J Nanomedicine. 2011;6:2749-2755.

88. Song WZ, Gong JX, Wang YQ, et al. Gold nanoflowers with mesoporous silica as "nanocarriers" for drug release and photothermal therapy in the treatment of oral cancer using near-infrared (NIR) laser light. J Nanopart Res. 2016;18:101.

89. Sulfikkarali N, Krishnakumar N, Manoharan S, Nirmal RM. Chemopreventive efficacy of naringenin-loaded nanoparticles in 7,12dimethylbenz(a)anthracene induced experimental oral carcinogenesis. Pathol Oncol Res. 2013;19(2):287-296.

90. Abbasi MM, Monfaredan A, Hamishehkar H, Seidi K, JahanbanEsfahlan R. Novel DOX-MTX nanoparticles improve oral SCC clinical outcome by down regulation of lymph dissemination factor VEGF-C expression in vivo: oral and IV modalities. Asian Pac J Cancer Prev. 2014;15(15):6227-6232.

91. Lin M, Wang D, Liu S, et al. Cupreous complex-loaded chitosan nanoparticles for photothermal therapy and chemotherapy of oral epithelial carcinoma. ACS Appl Mater Interfaces. 2015;7(37):20801-20812.

92. Kreimann EL, Itoiz ME, Longhino J, Blaumann H, Calzetta O, Schwint AE. Boron neutron capture therapy for the treatment of oral cancer in the hamster cheek pouch model. Cancer Res. 2001;61(24):8638-8642.

93. Molinari AJ, Thorp SI, Portu AM, et al. Assessing advantages of sequential boron neutron capture therapy (BNCT) in an oral cancer model with normalized blood vessels. Acta Oncol. 2015;54(1):99-106.

94. Garabalino MA, Heber EM, Monti Hughes A, et al. Boron biodistribution for BNCT in the hamster cheek pouch oral cancer model: combined administration of BSH and BPA. Appl Radiat Isot. 2014;88:64-68.

95. Suzuki M, Kato I, Aihara T, et al. Boron neutron capture therapy outcomes for advanced or recurrent head and neck cancer. J Radiat Res. 2014;55(1):146-153.

96. Heber EM, Kueffer PJ, Lee MW Jr, et al. Boron delivery with liposomes for boron neutron capture therapy (BNCT): biodistribution studies in an experimental model of oral cancer demonstrating therapeutic potential. Radiat Environ Biophys. 2012;51(2):195-204. 
97. Heber EM, Hawthorne MF, Kueffer PJ, et al. Therapeutic efficacy of boron neutron capture therapy mediated by boron-rich liposomes for oral cancer in the hamster cheek pouch model. Proc Natl Acad Sci US A. 2014;111(45):16077-16081.

98. Sugano M, Negishi Y, Endo-Takahashi Y, et al. Gene delivery system involving Bubble liposomes and ultrasound for the efficient in vivo delivery of genes into mouse tongue tissue. Int J Pharm. 2012; 422(1-2):332-337.

99. Lecaros RL, Huang L, Lee TC, Hsu YC. Nanoparticle delivered VEGF-A siRNA enhances photodynamic therapy for head and neck cancer treatment. Mol Ther. 2016;24(1):106-116.

100. Chen WH, Lecaros RL, Tseng YC, Huang L, Hsu YC. Nanoparticle delivery of HIF $1 \alpha$ siRNA combined with photodynamic therapy as a potential treatment strategy for head-and-neck cancer. Cancer Lett. 2015;359(1):65-74.

101. Wang B, Wang JH, Liu Q, et al. Rose-Bengal-conjugated gold nanorods for in vivo photodynamic and photothermal oral cancer therapies. Biomaterials. 2014;35(6):1954-1966.

102. Popovtzer A, Mizrachi A, Motiei M, et al. Actively targeted gold nanoparticles as novel radiosensitizer agents: an in vivo head and neck cancer model. Nanoscale. 2016;8(5):2678-2685.

103. Gherman C, Tudor MC, Constantin B, et al. Pharmacokinetics evaluation of carbon nanotubes using FTIR analysis and histological analysis. J Nanosci Nanotechnol. 2015;15(4):2865-2869.
104. Neagoe IB, Braicu C, Matea C, et al. Efficient siRNA delivery system using carboxilated single-wall carbon nanotubes in cancer treatment. J Biomed Nanotechnol. 2012;8(4):567-574.

105. Damascelli B, Patelli GL, Lanocita R, et al. A novel intraarterial chemotherapy using paclitaxel in albumin nanoparticles to treat advanced squamous cell carcinoma of the tongue: preliminary findings. AJR Am J Roentgenol. 2003;181(1):253-260.

106. Al-Ghananeem AM, Malkawi AH, Muammer YM, et al. Intratumoral delivery of paclitaxel in solid tumor from biodegradable hyaluronan nanoparticle formulations. AAPS PharmSciTech. 2009;10(2): $410-417$.

107. Damascelli B, Patelli G, Ticha V, et al. Feasibility and efficacy of percutaneous transcatheter intraarterial chemotherapy with paclitaxel in albumin nanoparticles for advanced squamous-cell carcinoma of the oral cavity, oropharynx, and hypopharynx. J Vasc Interv Radiol. 2007;18(11):1395-1403.

108. Fury MG, Sherman EJ, Rao SS, et al. Phase I study of weekly nabpaclitaxel + weekly cetuximab + intensity-modulated radiation therapy (IMRT) in patients with stage III-IVB head and neck squamous cell carcinoma (HNSCC). Ann Oncol. 2014;25(3):689-694.
International Journal of Nanomedicine

\section{Publish your work in this journal}

The International Journal of Nanomedicine is an international, peerreviewed journal focusing on the application of nanotechnology in diagnostics, therapeutics, and drug delivery systems throughout the biomedical field. This journal is indexed on PubMed Central, MedLine, CAS, SciSearch $®$, Current Contents ${ }^{\circledR} /$ Clinical Medicine,

\section{Dovepress}

Journal Citation Reports/Science Edition, EMBase, Scopus and the Elsevier Bibliographic databases. The manuscript management system is completely online and includes a very quick and fair peer-review system, which is all easy to use. Visit http://www.dovepress.com/ testimonials.php to read real quotes from published authors. 